\title{
Communication \\ Antibiotic Resistance and Genotypes of Mycoplasma genitalium during a Resistance-Guided Treatment Regime in a German University Hospital
}

\author{
Roger Dumke $^{1, *}$ and Petra Spornraft-Ragaller ${ }^{2}$ \\ 1 Institut für Medizinische Mikrobiologie und Virologie, Universitätsklinikum, Technische Universität Dresden, \\ Fetscherstrasse 74, 01307 Dresden, Germany \\ 2 Klinik und Poliklinik für Dermatologie, Universitätsklinikum, Technische Universität Dresden, \\ Fetscherstrasse 74, 01307 Dresden, Germany; Petra.Spornraft-Ragaller@uniklinikum-dresden.de \\ * Correspondence: roger.dumke@tu-dresden.de
}

Citation: Dumke, R.;

Spornraft-Ragaller, P. Antibiotic

Resistance and Genotypes of

Mycoplasma genitalium during a Resistance-Guided Treatment Regime in a German University Hospital. Antibiotics 2021, 10, 962. https:// doi.org/10.3390/antibiotics10080962

Academic Editor: Owen B. Spiller

Received: 9 July 2021

Accepted: 5 August 2021

Published: 10 August 2021

Publisher's Note: MDPI stays neutral with regard to jurisdictional claims in published maps and institutional affiliations.

Copyright: (c) 2021 by the authors. Licensee MDPI, Basel, Switzerland. This article is an open access article distributed under the terms and conditions of the Creative Commons Attribution (CC BY) license (https:// creativecommons.org/licenses/by/ $4.0 /)$.

\begin{abstract}
The treatment of infections from the sexually transmitted pathogen Mycoplasma genitalium is hampered by the rapidly increasing resistance to the recommended first- (macrolides) and second-line antibiotics (quinolones). Thus, resistance-guided therapy (RGT) is key for its successful eradication but the efficiency of this approach can be influenced by re-infections and treatment failures. The typing of strains is helpful to distinguish between ongoing colonization, re-infection or the development of resistance. In the present study, $m g p B$ and MG_309 types as well as mutations associated with macrolide, quinolone and tetracycline resistance of strains in M. genitalium-positive samples accumulated in the years 2019 and 2020 at a university hospital were analyzed. Fifty-eight positive first and sixteen positive follow-up samples from patients ( $96.6 \%$ male, $84.5 \%$ men who have sex with men, 74.1\% HIV-positive) were included. Twenty-three $m g p B$ types (seven new types), nine MG_309 types and thirty-four $m g p B / M G \_309$ types were identified. The prevalence of mutations associated with macrolide, quinolone and tetracycline resistance was $56.9 \%, 10.3 \%$ and $6.8 \%$, respectively. Despite the fact that many asymptomatic patients were not treated and tests of cure were impossible in different cases, the preliminary rate of successful eradication (93.3\%) in this study is promising for the continuation of the RGT strategy.
\end{abstract}

Keywords: sexually transmitted infection; Mycoplasma genitalium; antibiotic resistance; genotyping; resistance-guided therapy

\section{Introduction}

Mycoplasma genitalium is a Mollicutes species characterized by a strongly reduced genome $(5.8 \mathrm{Mbp})$ resulting in limited metabolic capabilities and virulence factors. The most striking feature is the lack of a classic cell wall. Between humans, as the only known natural hosts, M. genitalium is sexually transmitted and occurs predominantly among people with high-risk sexual behaviors (e.g., men who have sex with men (MSM)) [1-3]. The microorganisms cause non-gonococcal urethritis (NGU) and are associated with cervicitis and pelvic inflammatory disease [4-6]. M. genitalium has been detected in 10 to $25 \%$ of patients with NGU resulting in persistent symptoms in up to $41 \%$ of men after treatment failure (reviewed in $[4,6]$ ). However, the evaluation of prevalence is difficult as many infected patients are asymptomatic [3,7-9]. Due to the intrinsic resistance to all betalactam antibiotics and the narrowed efficacy (22-45\%) of doxycycline [10], options for the treatment of infections are limited. The European guideline for the treatment of M. genitalium infections [11] recommends azithromycin as first-line and moxifloxacin as second-line therapeutics. Unfortunately, the rate of strains with an acquired resistance has increased worldwide and has reached more than 50\% (macrolides) and 10\% (quinolones) especially in risk populations $[12,13]$. Recently, first strains showing mutations probably associated 
with a resistance to tetracycline were described [14,15], which, if spread in the future, could further affect the success of treatment concepts. Progress in the molecular characterization of the pathogen, investigations in cases of treatment failure and antimicrobial testing of the fastidiously growing bacteria in specialized laboratories in the last few years have resulted in the determination of resistance-associated mutations in $23 \mathrm{~S}$ rRNA (macrolides) and parC (fluoroquinolones) of $M$. genitalium and the development of methods for the detection of these transitions [7,8]. Although cure rates $>90 \%$ have been reached with a resistance-guided treatment (RGT) [16,17], the limited availability of approaches for resistance testing in ambulant settings hinders the establishment of an efficient regime to increase the nationwide eradication rates in practice. Furthermore, adherence problems, reinfections after unsafe sexual contacts, therapy failures and the development of resistance during therapy complicate the evaluation of the results of the recommended test-of-cure (ToC) samples. In this context, genotyping using a combination of determination of sequence differences in a highly variable region of the adhesin $M g p B$ and of the number of repeats in gene MG_309 is a reliable tool to characterize strains in first and follow-up samples [18] and helps to differentiate between ongoing colonization (treatment failure, acquisition of resistance) or re-infection. To extend the current data on this common sexually transmitted pathogen, we determined resistance-associated mutations and genotypes in $M$. genitalium strains sampled during an RGT regime in a tertiary care hospital.

\section{Results and Discussion}

This study summarizes the initial results after the introduction of a program of an extended characterization of $M$. genitalium strains in a university hospital in Germany. The presence of a reference laboratory locally and the close cooperation with clinical facilities allowed the consistent testing of all M. genitalium strains for markers of resistance as well the registration of patient data and of corresponding antibiotic therapy. Table 1 summarizes the information about the patients included in the study and the results of the characterization of M. genitalium strains. Among the 58 patients (mean age: 41.4 years, range: $20-63$ years), $96.6 \%(n=56)$ were men and $74.1 \%(n=43)$ were confirmed as HIVpositive. Forty-nine patients $(84.5 \%, n=49)$ identified themselves as MSM. As most of the patients were investigated during a regular screening for sexually transmitted infections in HIV-positive MSM, the majority of samples were rectal swabs ( $n=37,63.8 \%)$ followed by urethral swabs $(n=11,19.0 \%)$, urine $(n=8,13.8 \%)$ and vaginal swabs $(n=2,3.4 \%)$, respectively. Symptoms (exclusively signs of urethritis) were reported in only eight cases $(13.8 \%)$.

Table 1. Characteristics of patients and M. genitalium strains.

\begin{tabular}{|c|c|c|c|c|c|c|c|c|c|}
\hline Patient No. & Gender $^{1}$ & $\underset{\text { WSM }^{2}}{\text { MSM/MSW/ }}$ & $\begin{array}{c}\text { HIV } \\
\text { Status }\end{array}$ & Symptoms & Sample $^{3}$ & MRAM $^{4}$ & FRAM $^{5}$ & TRAM $^{6}$ & Genotype $^{7}$ \\
\hline 1 & $\mathrm{~m}$ & MSM & pos. ${ }^{8}$ & & US & no $^{9}$ & no & no & $\underline{231-13}$ \\
\hline 2 & $\mathrm{~m}$ & MSW & n.t. ${ }^{10}$ & & US & A2058G & no & no & $2-14$ \\
\hline 3 & $\mathrm{~m}$ & MSM & neg. 11 & & $\mathrm{U}$ & A2058G & no & no & n.d. ${ }^{12}-11$ \\
\hline 4 & $\mathrm{~m}$ & MSM & pos. & & RS & no & no & no & 134-10 \\
\hline 5 & $\mathrm{~m}$ & MSM & pos. & & RS & A2059G & no & n.d. & $111-10$ \\
\hline 6 & $\mathrm{~m}$ & MSM & pos. & & RS & A2059G & no & n.d. & $4-10$ \\
\hline 7 & $\mathrm{~m}$ & MSM & pos. & & RS & A2059G & no & n.d. & $4-10$ \\
\hline 8 & $\mathrm{~m}$ & MSM & pos. & & $\mathrm{U}$ & no & no & no & $62-10$ \\
\hline 9 & $\mathrm{~m}$ & MSM & pos. & & RS & A2059G & no & no & $4-10$ \\
\hline 10 & $\mathrm{~m}$ & MSM & pos. & & RS & no & no & no & $\underline{232-11}$ \\
\hline 11 & $\mathrm{~m}$ & MSM & pos. & & $\mathrm{R}$ & no & no & n.d. & $5-12$ \\
\hline 12 & $\mathrm{~m}$ & MSM & pos. & & $\mathrm{U}$ & A2059G & no & n.d. & 4-n.d. \\
\hline 13 & $\mathrm{~m}$ & MSW & neg. & & US & no & no & no & $133-9$ \\
\hline 14 & $\mathrm{~m}$ & MSW & n.t. & & US & no & no & no & 125-10 \\
\hline
\end{tabular}


Table 1. Cont.

\begin{tabular}{|c|c|c|c|c|c|c|c|c|c|}
\hline Patient No. & Gender $^{1}$ & $\underset{\text { WSM }^{2}}{\text { MSM/MSWI }}$ & $\begin{array}{l}\text { HIV } \\
\text { Status }\end{array}$ & Symptoms & Sample $^{3}$ & MRAM $^{4}$ & FRAM $^{5}$ & TRAM $^{6}$ & Genotype $^{7}$ \\
\hline 15 & $\mathrm{~m}$ & MSM & pos. & & RS & A2059G & no & n.d. & n.d.-n.d. \\
\hline 16 & $\mathrm{~m}$ & MSM & pos. & & $\mathrm{U}$ & A2059G & no & no & $6-12$ \\
\hline 17 & $\mathrm{~m}$ & MSM & pos. & & RS & A2059G & no & no & $4-11$ \\
\hline 18 & $\mathrm{~m}$ & MSM & pos. & & $\mathrm{U}$ & no & S83I & n.d. & 233-n.d. \\
\hline 19 & $\mathrm{~m}$ & MSM & pos. & & RS & A2058G & D87Y & C1192G & $113-11$ \\
\hline 20 & $\mathrm{~m}$ & MSM & pos. & & $\mathrm{U}$ & A2059G & no & no & n.d.-11 \\
\hline 21 & $f$ & WSM & n.t. & & VS & no & no & no & $2-14$ \\
\hline 22 & $\mathrm{~m}$ & MSM & pos. & & $\mathrm{U}$ & no & no & no & 234-14 \\
\hline 23 & $\mathrm{~m}$ & MSM & pos. & Urethritis & US & A2059G & no & no & $4-10$ \\
\hline 24 & $\mathrm{~m}$ & MSM & pos. & & RS & A2058G & S83I & $\begin{array}{l}\text { G966T and } \\
\text { G967T }\end{array}$ & 3-13 \\
\hline 25 & $\mathrm{~m}$ & MSM & neg. & & RS & A2059G & no & no & $4-11$ \\
\hline 26 & $\mathrm{~m}$ & MSM & pos. & & RS & no & no & n.d. & $8-12$ \\
\hline 27 & $\mathrm{~m}$ & MSM & pos. & & RS & A2058G & D87Y & C1192G & $12-13$ \\
\hline 28 & $\mathrm{~m}$ & MSM & pos. & & RS & A2059G & no & n.d. & $4-11$ \\
\hline 29 & $\mathrm{~m}$ & MSM & pos. & Urethritis & RS & A2059G & no & n.d. & $4-12$ \\
\hline 30 & $\mathrm{~m}$ & MSW & n.t. & & US & no & no & no & $5-11$ \\
\hline 31 & $\mathrm{~m}$ & MSM & pos. & & RS & no & no & no & $\underline{235}-10$ \\
\hline 32 & $\mathrm{~m}$ & MSM & pos. & & RS & A2058G & no & no & $4-10$ \\
\hline 33 & $\mathrm{~m}$ & MSW & n.t. & Urethritis & US & no & no & no & $2-12$ \\
\hline 34 & $\mathrm{~m}$ & MSM & neg. & & RS & A2059G & no & no & $4-10$ \\
\hline 35 & $f$ & WSM & pos. & & VS & no & no & no & $\underline{236}-11$ \\
\hline 36 & $\mathrm{~m}$ & MSM & neg. & Urethritis & RS & A2059G & no & no & $4-10$ \\
\hline 37 & $\mathrm{~m}$ & MSM & pos. & & RS & A2058G & S83I & n.d. & 3-n.d. \\
\hline 38 & $\mathrm{~m}$ & MSM & pos. & & RS & no & no & no & $113-14$ \\
\hline 39 & $\mathrm{~m}$ & MSM & pos. & & RS & A2059G & no & no & $52-18$ \\
\hline 40 & $\mathrm{~m}$ & MSM & neg. & & RS & A2059G & no & no & $4-9$ \\
\hline 41 & $\mathrm{~m}$ & MSM & pos. & & RS & no & no & n.d. & $111-11$ \\
\hline 42 & $\mathrm{~m}$ & MSM & pos. & & RS & no & no & no & 231-16 \\
\hline 43 & $\mathrm{~m}$ & MSM & pos. & & RS & no & no & n.d. & $\underline{233}-12$ \\
\hline 44 & $\mathrm{~m}$ & MSM & pos. & & RS & A2059G & no & no & $4-10$ \\
\hline 45 & $\mathrm{~m}$ & MSM & pos. & & RS & A2059G & no & no & $4-11$ \\
\hline 46 & $\mathrm{~m}$ & MSM & pos. & Urethritis & US & no & no & no & $4-12$ \\
\hline 47 & $\mathrm{~m}$ & MSM & pos. & & RS & no & no & no & $5-9$ \\
\hline 48 & $\mathrm{~m}$ & MSM & pos. & & RS & A2059G & no & no & $4-9$ \\
\hline 49 & $\mathrm{~m}$ & MSM & pos. & & RS & A2059G & no & no & $4-10$ \\
\hline 50 & $\mathrm{~m}$ & MSW & neg. & & US & no & no & no & $7-11$ \\
\hline 51 & $\mathrm{~m}$ & MSM & pos. & & RS & no & no & no & 237-9 \\
\hline 52 & $\mathrm{~m}$ & MSM & pos. & & RS & A2059G & no & no & $24-12$ \\
\hline 53 & $\mathrm{~m}$ & MSM & neg. & Urethritis & US & A2059G & no & no & $4-11$ \\
\hline 54 & $\mathrm{~m}$ & MSM & neg. & & RS & A2059G & no & no & $4-11$ \\
\hline 55 & $\mathrm{~m}$ & MSW & n.t. & Urethritis & US & no & S83I & n.d. & n.d.-n.d. \\
\hline 56 & $\mathrm{~m}$ & MSM & pos. & Urethritis & $\mathrm{U}$ & A2059G & no & no & $4-11$ \\
\hline 57 & $\mathrm{~m}$ & MSM & pos. & & RS & no & no & no & 231-14 \\
\hline 58 & $\mathrm{~m}$ & MSM & pos. & & RS & A2058G & no & no & $52-19$ \\
\hline
\end{tabular}

${ }^{1}$-f: female, m: male; ${ }^{2}$-women/men who have sex with men/women; ${ }^{3}$-RS: rectal swab, U: urine, US: urethral swab, VS: vaginal swab; ${ }^{4}$-macrolide resistance-associated mutation (nucleotide exchange in $23 \mathrm{~S}$ rRNA of $M$. genitalium, Escherichia coli numbering); ${ }^{5}$ _fluoroquinolone resistance-associated mutation (amino acid exchange in ParC of M. genitalium); ${ }^{6}$ — tetracycline resistance-associated mutation (nucleotide exchange in 16S rRNA of $M$. genitalium, E. coli numbering); ${ }^{7}$-mgpB type number of repeats in MG_309, bold and underlined: new $m g p B$ types; ${ }^{8}$ - positive; $^{9}$-no mutations; ${ }^{10}$ —not known/not tested; ${ }^{11}$-negative; ${ }^{12}$-not determined (sequencing failure, limited sample volume). 
Mutations associated with macrolide resistance (MRAM) were found in 33 strains (56.9\% of 58 patients). These were mainly A2059G (Escherichia coli numbering) transitions $(75.8 \%, n=25)$ whereas an A to $G$ change at position 2058 was confirmed in samples from the remaining patients. In contrast to only one of nine non-MSM patients (11.1\%), $65.3 \%(n=32)$ of strains from MSM exhibited macrolide resistance $(p=0.004$, OR 15.059, $95 \%$ CI 1.700-688.360). Interestingly, the strain in the urethral swab of a heterosexual man (\#50) showed an unusual C2084T mutation of 23S rRNA. Due to a negative followup test after treatment with azithromycin, an association of this nucleotide change with macrolide resistance is unlikely. Mutations leading to quinolone resistance were confirmed in strains from six patients $(10.3 \%)$ and resulted in an S83I $(4 \times)$ or a D87Y change $(2 \times)$ of the corresponding amino acid sequence of $\operatorname{ParC}(M$. genitalium numbering). Four of these cases of quinolone resistance were combined with macrolide resistance resulting in a multi-drug resistance rate of $6.9 \%$. Mutations in $16 \mathrm{~S}$ rRNA of $M$. genitalium associated with tetracycline resistance (G966T + G967T, C1192G; E. coli numbering) were found in three patients $(6.8 \%)$. Of note, a partial sequencing of $16 \mathrm{~S}$ rRNA was successful in only 44 of 58 samples and was done retrospectively. Patients carrying tetracycline-resistant M. genitalium were HIV-positive MSM and these strains showed additional mutations associated with macrolide and quinolone resistance.

MgpB and MG_309 genotyping was successful in 93.1\% $(n=54)$ and $91.4 \%(n=53)$ of strains in the first samples. The combined $m g p B-M G \_309$ type was found in $87.9 \%(n=51)$ of cases. Overall, nine MG_309, $23 \mathrm{mgpB}$ and $34 \mathrm{mgpB}-\mathrm{MG} 309$ types were found (Table 1, Figure 1) resulting in discrimination indices [19] of $0.821,0.844$ and 0.953 , respectively. Among the $m g p B$ types, seven new types were identified (Table 2, Tables S1 and S2) and type 4 was most common $(38.9 \%, n=21)$. The phylogenetic tree of $m g p B$ types shows that most of the strains $(96.3 \%, n=52)$ occurred in two clusters (Figure 1). Interestingly, the rate of macrolide resistance was $72.7 \%(24 / 33)$ in cluster 1 and only $21.0 \%(4 / 19)$ in cluster 2 ( $p=0.0005$, OR 10.0,95\% CI 2.256-50.374). Of the $m g p B$ type 4 strains (belonging to cluster 1$), 95 \%(20 / 21)$ were macrolide-resistant. All type 4-carrying patients were MSM and $71.4 \%(n=15)$ of them were HIV-positive.

The recommended ToC was performed in 30 patients $(51.7 \%$; including the abovementioned patient \#50). All of the 16 ToC-tested patients carrying strains without resistanceassociated mutations showed a $M$. genitalium-negative PCR (13 were treated with azithromycin and three with doxycycline because of accompanying sexually transmitted infections). Among the 14 patients infected with macrolide-resistant strains, 9 were successfully treated with moxifloxacin and 3 with doxycycline. Two patients remained positive after treatment with doxycycline (\#15 and 29, positive follow-up samples \#2f and 6f). Interestingly, in a man carrying a strain with a combined resistance to macrolides, quinolones and tetracyclines (patient \#27), the ToC was negative after therapy with doxycycline. Overall, the ToC was negative in 28 of the 30 treated patients (93.3\%).

Sixteen follow-up samples from eleven patients were M. genitalium-positive (Table 3) in the investigation period. The type of specimen corresponded with the first sampling. The interval between the first and subsequent positive sample ranged between 8 and 85 weeks. According to their asymptomatic status, only four of these patients were treated between the first and follow-up sample. In three cases (patients \#2, 5 and 7), a negative test result between both positive samples was demonstrated, suggesting re-infection in the time before the second positive test. This hypothesis was partly supported by the results of genotyping. In comparison with the first sampling, the strain in specimen \#1f showed the same genotype but differed in the occurrence of the mutation in 23S rRNA; in sample \#7f, differences in the presence of MRAMs and in the mgpB-MG_309 type were found whereas the strain in \#10f was identical in all available resistance and typing markers. As $m g p B-$ MG_309 typing has been characterized as highly discriminating and stable in different studies $[18,20,21]$, low-level colonization or sampling problems might be the reasons for the negative result of the intermediate rectal swab in the latter patient. Importantly, patients \#2 and 5 received moxifloxacin in the period before the second positive test. Due to 
co-infections, doxycycline was prescribed before follow-up sampling in cases \#2f and $6 f$. In sample \#6f, the available results of genotyping were identical between the samples. In the sample from one patient without an antibiotic therapy between sampling (\#3f), differences in at least one genotyping marker suggest a time-dependent colonization with genetically different strains whereas the available resistance and typing pattern of the strains of both samples in the remaining three patients without treatment (samples \#14f, $15 \mathrm{f}$ and 16f) were identical. Multiple M. genitalium-positive follow-up samples from three patients (\#15, 19 and 26) were analyzed (interval between the samples: up to 53 weeks). In the samples from patient \#19, the available results of the occurrence/non-occurrence of resistance-associated mutations and $m g p B / M G \_309$ typing were identical, indicating a long-term colonization (52 weeks) with the same multi-resistant $M$. genitalium genotype. Due to sequencing failures, specimens from patient \#15 were only partially comparable whereas samples from patient \#26 showed genotype differences between the strains in the first and second positive samples but the genotyping pattern remained identical in the further positive samples (up to 38 weeks).

Table 2. Distribution of $m g p B$ types of 54 M. genitalium clinical strains.

\begin{tabular}{|c|c|}
\hline $\begin{array}{c}\text { MgpB } \\
\text { Type }\end{array}$ & Number of Strains (\%) \\
\hline 4 & $21(38.9)$ \\
\hline 2 & $3(5.6)$ \\
\hline 5 & $3(5.6)$ \\
\hline$\underline{231}$ & $3(5.6)$ \\
\hline 3 & $2(3.7)$ \\
\hline 52 & $2(3.7)$ \\
\hline 111 & $2(3.7)$ \\
\hline 113 & $2(3.7)$ \\
\hline$\underline{233}$ & $2(3.7)$ \\
\hline 6 & $1(1.8)$ \\
\hline 7 & $1(1.8)$ \\
\hline 8 & $1(1.8)$ \\
\hline 12 & $1(1.8)$ \\
\hline 24 & $1(1.8)$ \\
\hline 62 & $1(1.8)$ \\
\hline 125 & $1(1.8)$ \\
\hline 133 & $1(1.8)$ \\
\hline 134 & $1(1.8)$ \\
\hline$\underline{232}$ & $1(1.8)$ \\
\hline$\underline{234}$ & $1(1.8)$ \\
\hline$\underline{235}$ & $1(1.8)$ \\
\hline$\underline{236}$ & $1(1.8)$ \\
\hline$\underline{237}$ & $1(1.8)$ \\
\hline
\end{tabular}

bold and underlined: new $m g p B$ types. 


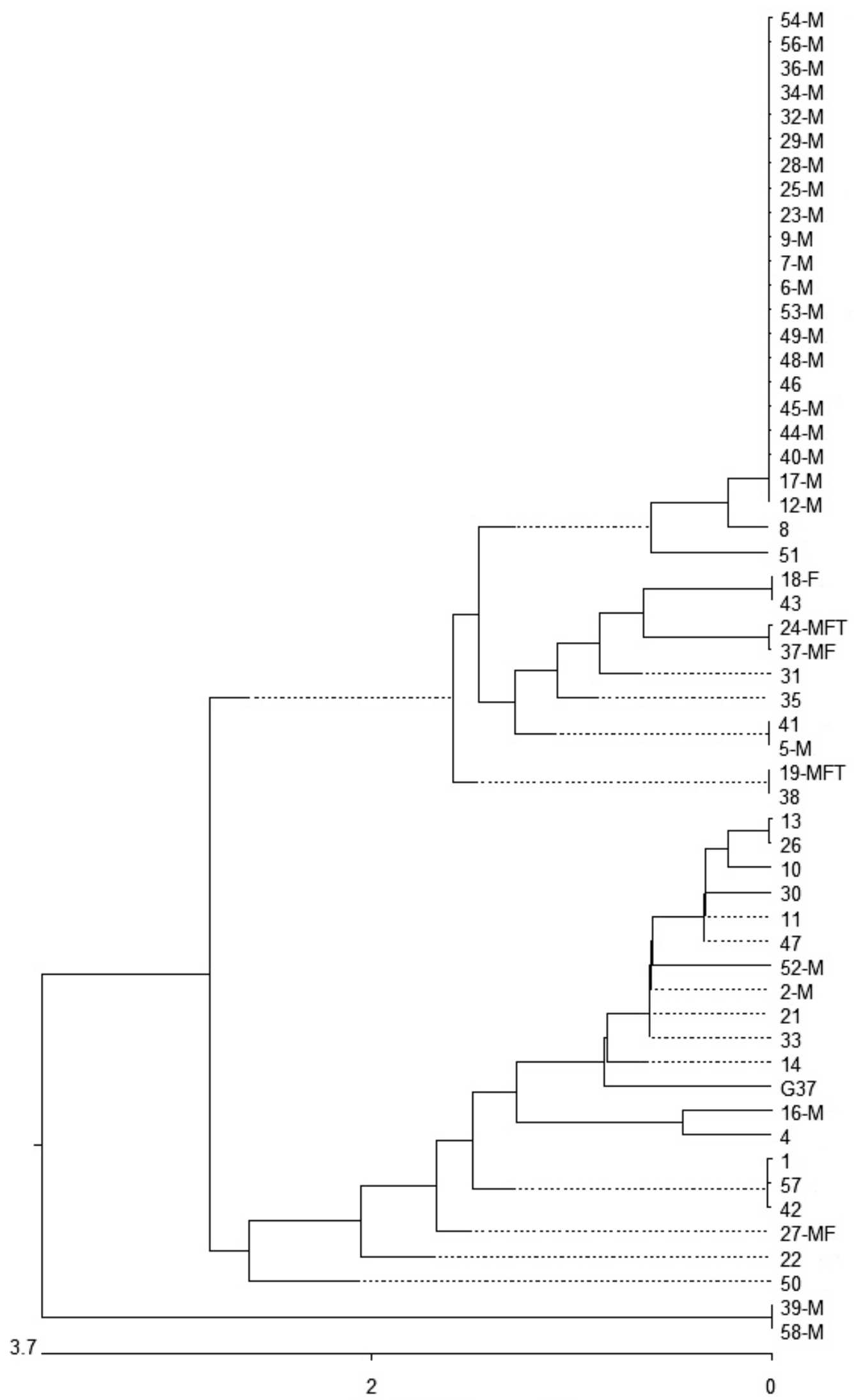

Figure 1. Similarity of partial mgpB sequences of type strain G37 and 54 M. genitalium clinical strains. M: strain with a macrolide resistance-associated mutation; F: strain with a fluoroquinolone resistance-associated mutation; T: strain with a tetracycline resistance-associated mutation. Bold and underlined: new types in comparison with the types described in Supplementary Table S1. Nucleotide substitution per 100 residues. 
Table 3. Characteristics of M. genitalium strains in follow-up samples.

\begin{tabular}{|c|c|c|c|c|c|c|c|}
\hline $\begin{array}{l}\text { M. genitalium-Positive } \\
\text { Follow-Up Samples } \\
\text { (Belonging to Patient No. } \\
\text { in Table 1, Previous } \\
\text { Follow-Up Sample No.) }\end{array}$ & $\begin{array}{c}\text { Weeks after } \\
\text { Previous } \\
\text { Test }\end{array}$ & $\begin{array}{c}\text { Previous } \\
\text { Antibiotic } \\
\text { Treatment }\end{array}$ & $\begin{array}{c}\text { Negative Test } \\
\text { between First } \\
\text { and Follow-Up } \\
\text { Sample }\end{array}$ & MRAM & FRAM & TRAM & Genotype \\
\hline If (2) & 18 & $\operatorname{MOX}^{1}$ & yes & no & no & no & $2-14$ \\
\hline $2 f(15)$ & 8 & DOX $^{2}$ & no & A2059G & no & n.d. & $4-11$ \\
\hline $3 f(13)$ & 12 & & no & no & no & no & $3-8$ \\
\hline $4 \mathrm{f}(19)$ & 26 & & no & A2058G & $\mathrm{D} 87 \mathrm{Y}$ & C1192G & $113-11$ \\
\hline $5 f(26)$ & 15 & & no & A2059G & no & no & $4-10$ \\
\hline $6 f(29)$ & 13 & DOX & no & A2059G & no & no & $4-12$ \\
\hline $7 f(5)$ & 52 & MOX & yes & no & no & n.d. & $4-11$ \\
\hline $8 \mathrm{f}(15,3 \mathrm{f})$ & 34 & & no & A2059G & no & no & $4-$-n.d. \\
\hline $9 f(26,6 f)$ & 12 & & no & A2059G & no & no & $4-10$ \\
\hline $10 f(7)$ & 59 & & yes & A2059G & no & no & $4-10$ \\
\hline $11 \mathrm{f}(19,5 \mathrm{f})$ & 26 & & no & A2058G & D87Y & C1192G & $113-11$ \\
\hline $12 f(26,6 f, 10 f)$ & 17 & & no & A2059G & no & no & $4-10$ \\
\hline $13 f(26,6 f, 10 f, 13 f)$ & 9 & & no & A2059G & no & no & $4-10$ \\
\hline $14 \mathrm{f}(48)$ & 27 & & no & A2059G & no & no & $4-9$ \\
\hline $15 f(24)$ & 59 & & no & A2058G & S83I & $\begin{array}{c}\text { G966T } \\
\text { and } \\
\text { G967T }\end{array}$ & $3-13$ \\
\hline $16 f(12)$ & 85 & & no & A2059G & no & no & $4-10$ \\
\hline
\end{tabular}

The increasing rates of resistance of $M$. genitalium to the recommended first- and second-line antibiotics, including the occurrence of multi-drug-resistant strains, are a cause for concern for public health. To control infections, not only new antimicrobials but also extended surveillance programs, a wider availability of resistance testing and optimized treatment strategies are necessary [6-8]. This is especially the case for particular populations. With the high rate of HIV-positive people and of MSM, the investigated patients in this study belonged to high-risk groups for the acquisition of M. genitalium infections and for colonization with resistant strains [22-25]. This fact hampers the comparison of resistance rates and genotypes between these groups and those of the few non-MSM and HIV-negative M. genitalium carriers included in the study. The overall rates of macrolide and quinolone resistance of $56.9 \%$ and $10.3 \%$ were in the range of reports from other countries [12,13]. Comparable studies in Germany are rare. Recent data from an MSM-dominated population in Berlin, Germany, demonstrated a similar rate of quinolone resistance $(10.4 \%)$ but a higher rate of macrolide-resistant strains $(79.9 \%)$, indicating local differences in the antibiotic susceptibility of M. genitalium strains [25]. Practitioners and public health authorities must anticipate the variability of the resistance pattern of circulating strains depending not only on whether patients belong to risk groups but also on regional characteristics. These findings further emphasize the value of resistance tests prior to antibiotic treatment.

As doxycycline is not recommended among first-, second- and third-line antibiotics to treat M. genitalium infections [11], investigations to detect mutations of tetracyclinebinding sites in 16S rRNA probably associated with resistance are scarce. Furthermore, the importance of particular transitions for the resistance of strains has been derived from other species and is not confirmed by susceptibility tests with $M$. genitalium or by using 
subinhibitory concentrations of doxycycline to induce corresponding mutations in the $16 \mathrm{~S}$ rRNA of M. genitalium. In two recent reports from France [14,15], mutations associated with a resistance to tetracyclines were found in 6 of 106 strains (5.7\%) and 2 of 16 strains $(12.5 \%)$. Despite its unusual use for the treatment of M. genitalium infections, doxycycline is part of an RGT scheme developed in Australia to reduce the bacterial load until the result of resistance testing of the strain is available [16] or is recommended as a component of a non-quinolone option for treatment [26]. If the rate of tetracycline-resistant strains is increasing, the use of tetracycline as an alternative treatment as part of RGT and for post-exposure prophylaxis may be further limited.

In addition to their importance for the interpretation of M. genitalium-positive followup tests, genotyping results provide interesting aspects regarding the circulation of distinct types in human populations. In the present study, more than one-third of strains could be assigned to $m g p B$ type 4 in cluster 1 (all of them found in MSM) and this type is disproportionately associated with macrolide resistance. Despite the low rate of non-MSM with a confirmed $m g p B$ type among the patients $(n=8,13.8 \%)$, one of two women who have sex with men (WSM) and the men who have sex with women (MSW) belonged to cluster 2 (exception: woman \#35), supporting the hypothesis of a largely independent circulation of genotypes in both groups. This was also shown in a recent study [27]. After the investigation of strains sampled between the years 2014 and 2016 in Dresden (31.6\%) and between 2017 and 2018 in Berlin (38.6\%), type 4 was also the most common $m g p B$ type $[21,28]$. Furthermore, the results of reports from France and Spain demonstrated rates of type 4 strains of $23.8 \%$ and $27.8 \%$, respectively [20,27]. All these studies included a high percentage of MSM. In contrast, the frequency of genotype 4 strains remains relatively low $(<7 \%)$ if populations with presumably low rates of MSM are analyzed, as shown in Australia, South Africa and Spain [29-31]. The findings suggest an increased circulation of $m g p B$ type 4 among MSM, at least in Europe, which is linked to a high rate of macrolide resistance. However, the rate of macrolide-resistant strains in the present study (56.9\%) was lower in comparison with that found in Berlin [25]. Further nationwide studies are necessary to substantiate this preliminary result. Nevertheless, it can be assumed that the occurrence of $M$. genitalium strains among carriers with a particular preferred sexual behavior is polyclonal and appears to be different to that of other populations. In combination with a high rate of the prescription of macrolides among (HIV-positive) MSM, the genotypes in this specific group tend to demonstrate a higher rate of resistance to azithromycin. At this stage, it remains unclear if the predominance of $m g p B$ type 4 among MSM is the result of easier transmission during anal intercourse [20] or of the limited connectivity between the sexual networks of MSM and WSM/MSW [27].

This study has several limitations. Despite the more common occurrence in symptomatic men, rectal colonization with M. genitalium was described as asymptomatic in many patients [9]. Strains in all M. genitalium-positive samples within the study period were tested at our hospital for resistance-associated mutations; a decision on the antibiotic therapy of patients depended on the presence of symptoms and the possibility of partner treatment to avoid a development of resistance, antibiotic side effects and unnecessary treatment costs $[8,32]$. Furthermore, the exact rate of the spontaneous clearing of rectal M. genitalium colonization in asymptomatic patients is not known. Thus, the number of positive but untreated patients is relatively high. Secondly, the treatment of patients was carried out exclusively in outpatient departments of the hospital. Unfortunately, this fact is often associated with a relatively high number of patients missing for a ToC (e.g., further treatment in other offices) or their late re-appearance causing difficulties in evaluating the overall eradication success of RGT. The investigation of resistance markers especially $m g p B / M G \_309$ typing demonstrates on the one hand the possibility of the long-term colonization of patients (e.g., patient \#19) with strains showing identical resistance and typing markers but also of patients becoming infected with genetically different strains during the investigation period. Depending on the sexual behavior, both patterns of colonization have been described in previous studies $[20,21,33,34]$. 
In conclusion, the preliminary data of the present study confirm the high rate of antibiotic resistance among M. genitalium strains in a local group of patients with an increased risk of becoming infected with this pathogen. Furthermore, the results of typing demonstrate the polyclonal structure of the investigated strains with a dominance of $m g p B$ type 4, which is associated with a frequent occurrence in MSM and macrolide resistance. Compared with non-MSM patients, being MSM causes a 15-fold increase in the odds of harboring macrolide-resistant strains. The rates of tetracycline- and quinolone-resistant strains were relatively low but need further monitoring. Despite the detection of reinfections, which might influence the evaluation of RGT strategies, the results underline the importance of subsequent and early susceptibility testing to control the transmission of M. genitalium.

\section{Materials and Methods}

In this study, we collected all M. genitalium-positive samples between January 2019 and December 2020 in the University Hospital of Dresden, Germany. The gender and HIV status (if available) of patients, reported presence of symptoms, location of sampling and results of the follow-up tests were recorded. DNA was extracted using an automated system (EZ1; Qiagen, Hilden, Germany) and M. genitalium was detected by real-time PCR as recommended by the manufacturer (TIB MolBiol, Berlin, Germany). The DNA of positive samples was frozen at $-80{ }^{\circ} \mathrm{C}$ until a further analysis. Overall, strains in 58 first and 16 positive follow-up samples were characterized. Mutations in 23S rRNA and the parC gene of $M$. genitalium associated with a resistance to macrolides and quinolones as well as $m g p B-M G \_309$ genotypes were determined by PCR/Sanger sequencing as described previously $[21,25]$. Nucleotide changes in a part of the $16 \mathrm{~S}$ rRNA of $M$. genitalium were determined by a semi-nested PCR as reported [35] and using a new forward primer for the first amplification (MG16-1f, 5'-GCA ATG CCG CGT GAA CGA TGA AGG-3'). All obtained sequences were compared with the corresponding regions in the reference genome of strain G37 (GenBank accession no. NC_000908.2). Due to the small numbers, a twosided Fisher's exact test was performed for the comparison of phylogenetic M. genitalium clusters 1 and 2 as well as for the comparison of MSM and non-MSM patients regarding the frequency of macrolide resistance. The confidence interval of the OR was calculated from a logit model. For calculation, Stata version 15.1 (StataCorp LLC, College Station, TX, USA) was used.

Supplementary Materials: The following are available online at https:/ /www.mdpi.com/article/10 .3390 / antibiotics10080962/s1, Table S1 (designation of M. genitalium strains based on $m g p B$ typing) and Table S2 (sequences of new mgpB types) [36].

Author Contributions: Conceptualization, methodology, validation, formal analysis, investigation, data curation, writing — original draft preparation, review and editing, R.D. and P.S.-R. All authors have read and agreed to the published version of the manuscript.

Funding: The study was supported by a grant from the Robert-Koch-Institut for German reference laboratories.

Institutional Review Board Statement: This study was approved by the Institutional Review Board of the TU Dresden (no.: EK 189062009).

Informed Consent Statement: According to the decision of the Institutional Review Board, patient consent was not considered necessary due to the retrospective nature of the study.

Data Availability Statement: The data presented in this study are available on reasonable request from the corresponding author. The data are not publicly available due to data protection reasons.

Acknowledgments: We would like to thank Falko Tesch, Centre for Evidence-Based Healthcare, Technical University of Dresden, for reviewing our statistical analysis.

Conflicts of Interest: The authors declare no conflict of interest. 


\section{References}

1. Baumann, L.; Cina, M.; Egli-Gany, D.; Goutaki, M.; Halbeisen, F.S.; Lohrer, G.R.; Ali, H.; Scott, P.; Low, N. Prevalence of Mycoplasma genitalium in different population groups: Systematic review and meta-analysis. Sex. Transm. Infect. 2018, 94, 255-262. [CrossRef]

2. Fernández-Huerta, M.; Barberá, M.J.; Esperalba, J.; Fernandez-Naval, C.; Vall-Mayans, M.; Arando, M.; Serra-Pladevall, J.; Broto, C.; Zarzuela, F.; Rando, A.; et al. Prevalence of Mycoplasma genitalium and macrolide resistance among asymptomatic people visiting a point of care service for rapid STI screening: A cross-sectional study. Sex. Transm. Infect. 2020, 96, 300-305. [CrossRef] [PubMed]

3. Read, T.R.H.; Murray, G.L.; Danielewski, J.A.; Fairley, C.K.; Doyle, M.; Worthington, K.; Su, J.; Mokany, E.; Tan, L.T.; Lee, D.; et al. Symptoms, sites, and significance of Mycoplasma genitalium in men who have sex with men. Emerg. Infect. Dis. 2019, 25, 719-727. [CrossRef]

4. Horner, P.J.; Martin, D.H. Mycoplasma genitalium infection in men. J. Infect. Dis. 2017, 216, S396-S405. [CrossRef]

5. Wiesenfeld, H.C.; Manhart, L.E. Mycoplasma genitalium in women: Current knowledge and research priorities for this recently emerged pathogen. J. Infect. Dis. 2017, 216, S389-S395. [CrossRef]

6. Unemo, M.; Jensen, J.S. Antimicrobial-resistant sexually transmitted infections: Gonorrhoea and Mycoplasma genitalium. Nat. Rev. Urol. 2017, 14, 139-152. [CrossRef]

7. Gnanadurai, R.; Fifer, H. Mycoplasma genitalium: A Review. Microbiology 2020, 166, 21-29. [CrossRef]

8. Peel, J.; Aung, E.; Bond, S.; Bradshaw, C. Recent advances in understanding and combatting Mycoplasma genitalium. Fac. Rev. 2020, 9, 3. [CrossRef]

9. Latimer, R.L.; Shilling, H.S.; Vodstrcil, L.A.; Machalek, D.A.; Fairley, C.K.; Chow, E.P.F.; Read, T.R.; Bradshaw, C.S. Prevalence of Mycoplasma genitalium by anatomical site in men who have sex with men: A systematic review and meta-analysis. Sex. Transm. Infect. 2020, 96, 563-570. [CrossRef]

10. Bradshaw, C.S.; Jensen, J.S.; Waites, K.B. New horizons in Mycoplasma genitalium treatment. J. Infect. Dis. 2017, 216, S412-S419. [CrossRef]

11. Jensen, J.S.; Cusini, M.; Gomberg, M.; Moi, H. 2016 European guideline on Mycoplasma genitalium infections. J. Eur. Acad. Dermatol. Venereol. 2016, 30, 1650-1656. [CrossRef]

12. Machalek, D.A.; Tao, Y.; Shilling, H.; Jensen, J.S.; Unemo, M.; Murray, G.; Chow, E.P.F.; Low, N.; Garland, S.M.; Vodstrcil, L.A.; et al. Prevalence of mutations associated with resistance to macrolides and fluoroquinolones in Mycoplasma genitalium: A systematic review and meta-analysis. Lancet Infect. Dis. 2020, 20, 1302-1314. [CrossRef]

13. Fernández-Huerta, M.; Barberá, M.J.; Serra-Pladevall, J.; Esperalba, J.; Martínez-Gómez, X.; Centeno, C.; Pich, O.Q.; Pumarola, T.; Espasa, M. Mycoplasma genitalium and antimicrobial resistance in Europe: A comprehensive review. Int. J. STD AIDS 2020, 31, 190-197. [CrossRef]

14. Le Roy, C.; Touati, A.; Balcon, C.; Garraud, J.; Molina, J.M.; Berçot, B.; de Barbeyrac, B.; Pereyre, S.; Peuchant, O.; Bébéar, C. Identification of $16 \mathrm{~S}$ rRNA mutations in Mycoplasma genitalium potentially associated with tetracycline resistance in vivo but not selected in vitro in M. genitalium and Chlamydia trachomatis. J. Antimicrob. Chemother. 2021, 76, 1150-1154. [CrossRef]

15. Berçot, B.; Charreau, I.; Clotilde, R.; Delaugerre, C.; Chidiac, C.; Pialoux, G.; Capitant, C.; Bourgeois-Nicolaos, N.; Raffi, F.; Pereyre, S.; et al. High prevalence and high rate of antibiotic resistance of Mycoplasma genitalium infections in men who have sex with men. A sub-study of the ANRS Ipergay PrEP Trial. Clin. Infect. Dis. 2020, 66, 796-798. [CrossRef]

16. Durukan, D.; Read, T.R.H.; Murray, G.; Doyle, M.; Chow, E.P.F.; Vodstrcil, L.A.; Fairley, C.K.; Aguirre, I.; Mokany, E.; Tan, L.Y.; et al. Resistance-guided antimicrobial therapy using doxycycline-moxifloxacin and doxycycline-2.5 g azithromycin for the treatment of Mycoplasma genitalium infection: Efficacy and tolerability. Clin. Infect. Dis. 2020, 71, 1461-1468. [CrossRef]

17. Conway, R.J.; Cook, S.; Malone, C.; Bone, S.; Hassan-Ibrahim, M.O.; Soni, S. Resistance-guided treatment of Mycoplasma genitalium infection at a UK sexual health centre. Int. J. STD AIDS 2021, 23, 956462420987764.

18. Cazanave, C.; Charron, A.; Renaudin, H.; Bébéar, C. Method comparison for molecular typing of French and Tunisian Mycoplasma genitalium-positive specimens. J. Med. Microbiol. 2012, 61, 500-506. [CrossRef] [PubMed]

19. Hunter, P.R.; Gaston, M.A. Numerical index of the discriminatory ability of typing systems: An application of Simpson's index of diversity. J. Clin. Microbiol. 1988, 26, 2465-2466. [CrossRef]

20. Guiraud, J.; Lounnas, M.; Boissière, A.; Le Roy, C.; Elguero, E.; Banuls, A.L.; Bébéar, C.; Godreuil, S.; Pereyre, S. Lower mgpB diversity in macrolide-resistant Mycoplasma genitalium infecting men visiting two sexually transmitted infection clinics in Montpellier, France. J. Antimicrob. Chemother. 2021, 76, 43-47. [CrossRef]

21. Dumke, R.; Rust, M.; Glaunsinger, T. MgpB types among Mycoplasma genitalium strains from men who have sex with men in Berlin, Germany, 2016-2018. Pathogens 2019, 9, 12. [CrossRef]

22. Couldwell, D.L.; Jalocon, D.; Power, M.; Jeoffreys, N.J.; Chen, S.C.; Lewis, D.A. Mycoplasma genitalium: High prevalence of resistance to macrolides and frequent anorectal infection in men who have sex with men in western Sydney. Sex. Transm. Infect. 2018, 94, 406-410. [CrossRef]

23. Dionne-Odom, J.; Geisler, W.M.; Aaron, K.J.; Waites, K.B.; Westfall, A.O.; van der Pol, B.; Xiao, L. High prevalence of multidrugresistant Mycoplasma genitalium in human immunodeficiency virus-infected men who have sex with men in Alabama. Clin. Infect. Dis. 2018, 66, 796-798. [CrossRef] [PubMed] 
24. Jansen, K.; Steffen, G.; Potthoff, A.; Schuppe, A.K.; Beer, D.; Jessen, H.; Scholten, S.; Spornraft-Ragaller, P.; Bremer, V.; Tiemann, C. MSM Screening Study group. STI in times of PrEP: High prevalence of chlamydia, gonorrhea, and mycoplasma at different anatomic sites in men who have sex with men in Germany. BMC Infect. Dis. 2020, 20, 110. [CrossRef] [PubMed]

25. Dumke, R.; Ziegler, T.; Abbasi-Boroudjeni, N.; Rust, M.; Glaunsinger, T. Prevalence of macrolide- and fluoroquinolone-resistant Mycoplasma genitalium isolates in clinical specimens from men who have sex with men of two sexually transmitted infection practices in Berlin, Germany. J. Glob. Antimicrob. Resist. 2019, 18, 118-121. [CrossRef]

26. Doyle, M.; Vodstrcil, L.A.; Plummer, E.L.; Aguirre, I.; Fairley, C.K.; Bradshaw, C.S. Nonquinolone options for the treatment of Mycoplasma genitalium in the era of increased resistance. Open Forum Infect. Dis. 2020, 7, ofaa291. [CrossRef] [PubMed]

27. Fernández-Huerta, M.; Serra-Pladevall, J.; Esperalba, J.; Moreno-Mingorance, A.; Fernández-Naval, C.; Barberá, M.J.; Aparicio, D.; Pich, O.Q.; Pumarola, T.; Jensen, J.S.; et al. Single-locus-sequence-based typing of the $m g p B$ gene reveals transmission dynamics in Mycoplasma genitalium. J. Clin. Microbiol. 2020, 58, e01886-19. [CrossRef] [PubMed]

28. Dumke, R.; Thürmer, A.; Jacobs, E. Emergence of Mycoplasma genitalium strains showing mutations associated with macrolide and fluoroquinolone resistance in the region Dresden, Germany. Diagn. Microbiol. Infect. Dis. 2016, 86, 221-223. [CrossRef]

29. Plummer, E.L.; Murray, G.L.; Bodiyabadu, K.; Su, J.; Garland, S.M.; Bradshaw, C.S.; Read, T.R.H.; Tabrizi, S.N.; Danielewski, J.A. A custom amplicon sequencing approach to detect resistance associated mutations and sequence types in Mycoplasma genitalium. J. Microbiol. Methods 2020, 179, 106089. [CrossRef] [PubMed]

30. Laumen, J.G.E.; van Alphen, L.B.; Maduna, L.D.; Hoffman, C.M.; Klausner, J.D.; Medina-Marino, A.; Kock, M.M.; Peters, R.P.H. Molecular epidemiological analysis of Mycoplasma genitalium shows low prevalence of azithromycin resistance and a well-established epidemic in South Africa. Sex. Transm. Infect. 2021, 97, 152-156. [CrossRef]

31. Piñeiro, L.; Idigoras, P.; Cilla, G. Molecular typing of Mycoplasma genitalium-positive specimens discriminates between persistent and recurrent infections in cases of treatment failure and supports contact tracing. Microorganisms 2019, 7, 609. [CrossRef] [PubMed]

32. Ong, J.J.; Ruan, L.; Lim, A.G.; Bradshaw, C.S.; Taylor-Robinson, D.; Unemo, M.; Horner, P.J.; Vickerman, P.; Zhang, L. Impact of screening on the prevalence and incidence of Mycoplasma genitalium and its macrolide resistance in men who have sex with men living in Australia: A mathematical model. EClinicalMedicine 2021, 33, 100779. [CrossRef] [PubMed]

33. Ma, L.; Taylor, S.; Jensen, J.S.; Myers, L.; Lillis, R.; Martin, D.H. Short tandem repeat sequences in the Mycoplasma genitalium genome and their use in a multilocus genotyping system. BMC Microbiol. 2008, 8, 130. [CrossRef]

34. Hjorth, S.V.; Björnelius, E.; Lidbrink, P.; Falk, L.; Dohn, B.; Berthelsen, L.; Ma, L.; Martin, D.H.; Jensen, J.S. Sequence-based typing of Mycoplasma genitalium reveals sexual transmission. J. Clin. Microbiol. 2006, 44, 2078-2083. [CrossRef] [PubMed]

35. Jensen, J.S.; Borre, M.B.; Dohn, B. Detection of Mycoplasma genitalium by PCR amplification of the 16S rRNA gene. J. Clin. Microbiol. 2003, 41, 261-266. [CrossRef] [PubMed]

36. Sweeney, E.L.; Tickner, J.; Bletchly, C.; Nimmo, G.R.; Whiley, D.M. Genotyping of Mycoplasma genitalium suggests de novo acquisition of antimicrobial resistance in Queensland, Australia. J. Clin. Microbiol. 2020, 58, e00641-20. [CrossRef] [PubMed] 